\title{
Governança eletrônica sob perspectiva institucional: análise do portal de periódicos da Capes
}

\section{Eletronic governance from an institutional perspective: analyzing Capes portal of journals}

\author{
Gabriela Viale Pereira \\ Doutoranda do Programa de Pós-Graduação em \\ Administração (PPGAd) da Pontifícia Universidade \\ Católica do Rio Grande do Sul (PUCRS) \\ gabiviale@terra.com.br
}

Contextus

ISSNe 2178-9258

Organização: Comitê Científico Interinstitucional Editor Científico: Marcelle Colares Oliveira Avaliação: Double Blind Review pelo SEER/OJS Revisão: Gramatical, normativa e de formatação Recebimento: 15/08/2012 Aprovação: 27/12/2013

\author{
Marie Anne Macadar \\ Professora e Pesquisadora do Programa de Pós- \\ Graduação em Administração (PPGAd) da \\ Pontifícia Universidade Católica do Rio Grande do \\ Sul (PUCRS) \\ marie.macadar@pucrs.br
}

\author{
Vanessa Marques Daniel \\ Mestre em Administração pelo programa de Pós- \\ Graduação em Administração (PPGAd) da \\ Pontifícia Universidade Católica do Rio Grande do \\ Sul (PUCRS) \\ nessa.daniel@gmail.com
}

\begin{abstract}
RESUMO
Em um contexto de crescimento das Tecnologias de Informação e Comunicação nas organizações, surgiu a necessidade de adoção de tecnologia também nos governos, para a melhoria dos processos administrativos, da prestação de serviços públicos e da participação social, através de práticas de governança eletrônica. Este estudo buscou verificar como os fatores institucionais influenciam as organizações a implementar práticas de governança eletrônica. Para isso, foi proposto um modelo conceitual que busca identificar a influência de pressões coercitivas, normativas e miméticas na implementação de práticas de governança eletrônica, através de proposições de pesquisa. Utilizou-se a abordagem qualitativa de pesquisa, através do estudo de caso único sobre o Portal de Periódicos da Capes. Os resultados encontrados corroboram as proposições do modelo conceitual, sugerindo que a Capes foi influenciada por modelos bem-sucedidos no ambiente organizacional e por órgãos como o MEC e o governo federal na adoção dessa tecnologia.
\end{abstract}

Palavras-chave: Governo eletrônico. Governança eletrônica. e-Serviço público. Portal de Periódicos da Capes. Pesquisa qualitativa.

\begin{abstract}
In a context of ICT growth in organizations, governments have been required to employ technology to improve administrative procedures, public services and social participation through electronic governance practices. Therefore, the present study searched to verify how institutional factors influence organizations to implement electronic governance practices. In order to answer this question, a conceptual model was proposed seeking to identify the influence of coercive pressures, mimetic and normative practices in implementing electronic governance through research propositions. A qualitative research approach was used and a single case study of CAPES Portal of Journals was carried out. The research findings corroborate the propositions of the conceptual model, suggesting that there is influence of institutional factors in the form of coercive, normative and mimetic mechanisms in implementing electronic governance.
\end{abstract}

Keywords: Electronic Government. Electronic Governance. E-government services. CAPES Portal of Journals. Qualitative research. 


\section{INTRODUÇÃO}

Nas últimas décadas, o cenário social da vida humana tem se remodelado pela revolução tecnológica concentrada nas Tecnologias de Informação e Comunicação (TICs) (CASTELLS, 1999). No contexto organizacional, as TICs têm se tornado uma das principais áreas estratégicas, sendo a Internet uma importante ferramenta que permite maior eficiência e eficácia nos processos administrativos e organizacionais das instituições.

Diante desse cenário de transformações tecnológicas, surge a necessidade de uma efetiva gestão de TIC nos governos, fator enfatizado pela reforma da gestão pública idealizada nos anos 90. Conforme constata Castells (1999), a melhoria do sistema brasileiro de comunicação foi fundamental para que o país pudesse se alinhar, naquele período, à supervia global emergente da sociedade da informação. A partir do uso das TICs na gestão pública, surgiu o termo governança eletrônica (e-governo ou governo eletrônico). Assim, a governança eletrônica consiste no uso de TIC na administração pública, tanto para a sua melhoria como para a prestação de serviços eletrônicos e o incremento da participação do cidadão na tomada de decisões de governo (CUNHA et al., 2007).
É nesse contexto, de modernização e uso de TIC nas organizações públicas, que esta pesquisa está inserida. Buscou-se na teoria institucional a lente teórica de pesquisa. Essa teoria sugere que as organizações tendem a adotar estruturas semelhantes, formando um campo homogêneo, para obtenção de reconhecimento no ambiente em que estão inseridas. Acredita-se que a teoria institucional possui construtos que permitem a análise do ambiente organizacional da gestão pública e a influência que pode ocorrer dos fatores institucionais na adoção de tecnologia nas organizações. Assim, a teoria institucional postula que as ações organizacionais estão relacionadas com as irracionalidades do contexto institucional das organizações e com os sistemas culturais embutidos nelas (AVGEROU, 2001).

O presente trabalho se encontra no limiar dos estudos de adoção de TIC em entidades públicas, através de uma perspectiva institucional, enfatizando a influência do contexto organizacional nas decisões de implementação de práticas de governança eletrônica pelas organizações em serviços prestados aos cidadãos (eServiços públicos). Assim, este estudo buscou responder a seguinte questão de pesquisa: Como os fatores institucionais influenciam as organizações para a implementação de práticas de governança 
eletrônica? Dessa forma, o objetivo foi verificar como os fatores institucionais influenciam as organizações a implementar práticas de governança eletrônica. Para isso, foi proposto um modelo conceitual que buscou identificar a influência de pressões coercitivas, normativas e miméticas na implementação de práticas de governança eletrônica, através de proposições de pesquisa.

Justifica-se a importância desta pesquisa, pela atual e constante preocupação com relação ao uso de TIC nos governos. No Brasil, o tema governo eletrônico vem sendo abordado por diversos autores, sob diferentes aspectos, como Cunha et al. (2009), Knight et al. (2007), Diniz et al. (2009), Rodriguez et al. (2007), Guimarães e Medeiros (2006), Jóia (2009), Laia (2009), Laia et al. (2011). No cenário internacional, Heeks e Bailur (2007) identificaram um crescimento da produção científica sobre governo eletrônico nos últimos anos, evidenciando preocupação com o tema. Porém, conforme destacam esses autores, existem limitações teóricas e metodológicas nas pesquisas da área. Nessa mesma linha de raciocínio, Yildiz (2007) e Gil-Garcia e Luna-Reyes (2006) ainda apontam a imprecisão do conceito e a simplificação dos processos de desenvolvimento de governo eletrônico no ambiente político e institucional.

\section{FUNDAMENTAÇÃO TEÓRICA}

Para apoiar este estudo, buscou-se uma lente teórica que permitisse a identificação do papel do ambiente social na tomada de decisão das instituições públicas para a adoção de inovações tecnológicas. A perspectiva institucional permite a análise de como o ambiente organizacional influencia na adoção de tecnologia na administração pública. Os fatores institucionais identificados no ambiente organizacional são componentes essenciais para compreensão da adoção de TIC que transpõem as fronteiras organizacionais (KING et al., 1994). Tais fatores são identificados por Scott (2008) como regulatórios, normativos e culturalcognitivos, que exercem influência na adoção de sistemas de informação (SIs) no contexto da administração pública. Assim, a teoria institucional estuda aspectos da estrutura social, considerando os processos pelos quais as estruturas, incluindo esquemas, regras, normas e rotinas, se estabelecem como diretrizes para o comportamento social (SCOTT, 2004).

\subsection{Os Pilares da Teoria Institucional}

Para Scott (2008), as instituições são constituídas de elementos reguladores, 
normativos e cultural-cognitivos que fornecem, junto com atividades e recursos associados, estabilidade e significado à vida social, elementos esses considerados centrais de estruturas institucionais. Esses elementos foram propostos com base na definição de instituições, sendo eles sistemas vitais e de apoio para as instituições (SCOTT, 2008). As dimensões definidas pelo autor mostram a variação dos pressupostos de um elemento sobre o outro e os diferentes argumentos dos teoristas.

Assim, esses elementos são considerados como pilares que provêm uma base para a legitimidade, uma condição que reflete conformidade com regras e leis, suporte normativo ou alinhamento com estruturas culturalcognitivas. As bases da legitimidade associadas com os três elementos diferem entre si, em que uma visão reguladora verifica se a organização é legalmente estabelecida e se está agindo de acordo com as leis e os regulamentos pertinentes, uma orientação normativa enfatiza obrigações morais e a orientação culturalcognitiva exibe um modo culturalmente constituído (SCOTT, 2008).

\subsubsection{O pilar regulatório}

De acordo com Scott (2008), todas as escolas enfatizam os aspectos regulatórios das instituições, regularizando o comportamento. Contudo, as escolas associadas com o pilar regulatório explicitam mais processos como o estabelecimento de regras, monitoramento e sanção. Assim, o autor define o processo regulatório como a capacidade de estabelecer regras, inspecionar o seu cumprimento e manipular sanções, como recompensas e punições, a fim de influenciar o comportamento. Ainda para o autor, esses processos podem ser operados por mecanismos informais ou ainda por atores especializados.

O principal mecanismo de controle do pilar regulatório, de acordo com DiMaggio e Powell (1983), é a coerção. Segundo os autores, esse mecanismo deriva de influências políticas e do problema da legitimidade, tanto de pressões formais quanto informais exercidas por organizações das quais uma organização depende ou por expectativas culturais da sociedade. Esse ambiente legal existente afeta diversos aspectos do comportamento e da estrutura das organizações, tornando-as homogêneas dentro de determinados domínios e dependentes de conformidade com as instituições maiores (DIMAGGIO; POWELL, 1983). Assim, de acordo com Scott (2008), as instituições trabalham 
tanto para reprimir quanto para capacitar o comportamento social.

Segundo Scott (2008), os ingredientes centrais do pilar regulatório, como força e sanções, podem ser suavizados pela existência de regras como tradições informais ou leis formais, mas, mesmo assim, atores poderosos podem impor sua vontade através do uso de ameaças de sanções. Um exemplo que o autor traz relacionado ao governo é o caso de programas federais que impõem conformidades de cooperação local segura provendo fundos para apoiar programas desejados (SCOTT, 2008).

Para Scott (2008), as organizações podem ser apoiadas apenas por um pilar, porém, conforme o tempo passa e ocorrem mudanças, as organizações passam a ser apoiadas por diferentes pilares. É necessário entender como instituições regulatórias funcionam e como elas interagem com outras organizações. Assim, o autor aborda que regras precisam ser interpretadas, incentivos e sanções precisam ser concebidos.

\subsubsection{O pilar normativo}

De acordo com Scott (2008), o pilar normativo inclui um conjunto de valores e normas em um contexto social, introduzindo uma dimensão prescritiva, avaliativa e obrigatória nesse contexto. Valores são conceitos e atributos do que é desejável, além de estruturas e comportamentos comparados a um padrão de referência. Normas definem formas legítimas de perseguir os objetivos desejados, especificando como as coisas devem ser feitas. Ainda para o autor, sistemas normativos são vistos como imposições ao comportamento social, autorizando e habilitando a ação social. Os sistemas normativos “[...] conferem direitos como também responsabilidades; privilégios como também deveres; licenças como também mandatos" (SCOTT, 2008, p. 55).

A concepção normativa de instituições é trazida por Scott (2008) como uma das mais disseminadas pelos sociólogos, pois considera que convicções comuns e valores são mais prováveis de constituírem uma base importante para a ordem. Para eles, convicções sociais e normas possuem uma influência estabilizadora da ordem social (SCOTT, 2008).

Com relação à concepção normativa das instituições, DiMaggio e Powell (1983) identificam que a mudança organizacional isomórfica deriva principalmente da profissionalização, para estabelecer uma base cognitiva além da legitimação, para a autonomia de sua profissão. Para os autores, o apoio da educação formal, com especialistas universitários e a constituição de redes 
profissionais são fontes de isomorfismo, pois são importantes centros de desenvolvimento de normas organizacionais.

\subsubsection{O pilar cultural-cognitivo}

No pilar cultural-cognitivo, as instituições são vistas como a cultura da organização, pois o foco está nos esquemas cognitivos e modelos mentais que fornecem um conjunto de padrões para a construção de significados (SCOTT, 2008). O autor ainda enfatiza que essa dimensão é a principal distinção do neoinstitucionalismo na Sociologia e nos estudos organizacionais, em que a mediação entre os estímulos do mundo externo e a reação do organismo individual é um conjunto de representações simbólicas interiorizadas do mundo.

A concepção cultural-cognitiva proposta por Scott (2008) enfatiza a importância dos símbolos e significados, reconhecendo que processos interpretativos internos são moldados pelas estruturas culturais externas. Para ele, "[...] uma concepção cultural-cognitiva de instituições enfatiza o papel central desempenhado pela construção socialmente mediada de uma estrutura comum de significado" (p. 59).

De acordo com DiMaggio e Powell (1983), no contexto organizacional, o isomorfismo mimético é uma das principais manifestações do pilar culturalcognitivo. Isso ocorre devido a incertezas simbólicas do ambiente ou metas organizacionais confusas e ambíguas, estimulando a busca por modelos organizacionais. De acordo com os autores, as organizações tendem a copiar práticas de outras organizações em seu campo das quais elas percebam ser mais legítimas e bem-sucedidas. Assim, apesar da busca pela diversidade, as organizações tendem a ser cada vez mais homogêneas em seu campo organizacional (DIMAGGIO; POWELL, 1983).

\subsection{Governança Eletrônica}

O uso de TIC no setor público, tratado de governo eletrônico nos anos 1990, passou a ser chamado recentemente de governança eletrônica ou e-Governo, por compreender conceitos mais abrangentes, como a aplicação das TICs na governança pública (CUNHA et al., 2007; BARBOSA et al., 2007). O conceito de eGovernança é “[...] o exercício de uma nova forma e possibilidade de governar, com participação de ampla rede de atores" (CUNHA et al., 2007, p. 560).

A governança eletrônica engloba tanto o uso de TIC para a melhoria da gestão pública (e-Administração pública), dos serviços oferecidos aos cidadãos (eServiços públicos), bem como da ampliação da participação do cidadão no 
que diz respeito às práticas de governo (eDemocracia) (CUNHA et al., 2007).

Nessa mesma linha, de acordo com Barbosa et al. (2007), essa visão mais ampla de governança eletrônica considera os aspectos internos à administração pública, como processos, relacionamentos e estruturas, aspectos externos como serviços públicos e participação, e controle. Assim, os autores sugerem três dimensões de aplicação de TIC na gestão pública, a saber: e-Administração pública: está associada à utilização de TIC para melhoria dos processos governamentais e do trabalho interno do setor público; e-Serviços públicos: está associado à utilização de tecnologias para melhoria na prestação de serviços aos cidadãos através da criação de canais digitais para acesso e entrega de serviços; e-Democracia: está associada ao uso de TIC para permitir a participação do cidadão no processo de tomada de decisão.

As ações de governança eletrônica devem estar alinhadas às estratégias de governo, através de estruturas de Governança de TIC responsáveis pelos ativos tecnológicos das organizações e pelos e-Serviços públicos prestados, buscando eficiência e eficácia desses serviços (BARBOSA et al., 2007). De acordo com os autores, essas ações devem atender quatro necessidades: accountability; governança; integração transversal; transparência; participação democrática. As três dimensões propostas por esses autores ainda podem ser subdivididas em duas dimensões maiores, a de e-Governo - com as dimensões de eServiços públicos e de e-Administração pública -, e de e-Democracia.

\section{MODELO TEÓRICO DA PESQUISA}

Com base no referencial teórico adotado nesta pesquisa, foi construído um modelo conceitual através de um processo contínuo de reflexão teórica e prática. A Figura 1 apresenta o modelo conceitual da pesquisa. Os três pilares da Teoria Institucional propostos por Scott (2008) possuem mecanismos de controle que consistem, respectivamente, em pressões coercitivas, normativas e miméticas. Conforme Orlikowski e Barley (2001), a teoria institucional expande o foco de análise de TIC, permitindo analisar quão influentes são as forças sociais e históricas, compreendidas entre leis, normas e aspectos culturais, que também são afetadas pelas ações organizacionais, e como as tecnologias são moldadas por essas influências institucionais.

Considerando os pressupostos da teoria institucional, as instituições podem adotar práticas institucionalizadas com uso de tecnologia para obtenção de legitimidade, mesmo não sendo a melhor opção para sua estratégia organizacional (TEO et al., 2003). O contrário pode 
ocorrer quando práticas inovadoras são adotadas no lugar de processos legitimados, resultando na perda de legitimidade no ambiente organizacional, exceto com organizações reconhecidas e influentes que tendem a legitimar novos padrões (TEO et al., 2003; RODRIGUEZ et al., 2007). Tais aspectos foram discutidos no trabalho de Pereira, Macadar e Becker (2012), em que foi identificado que instituições sofrem pressões coercitivas, normativas e miméticas para utilização de e-Serviços públicos que se tornam legítimos, pois são implantados por organizações influentes na área de Educação.

A legitimação de padrões pode ocorrer por diversos fatores. Considerando o pilar regulatório, conforme sugerem Diniz et al. (2009), pode ocorrer através da elaboração de políticas públicas voltadas à tecnologia para aumento da qualidade na prestação de serviços públicos, ou através de incentivos e disponibilização de recursos para adoção de TIC na organização para prestação de serviços. Considerando o pilar normativo, através da aceitação por instituições dominantes e do principais (TEO et al., 2003), podendo haver coerção quanto à conformidade com regulamentações e normas, quando isso ocorre nas matrizes. A partir dessas considerações, propõe-se que: reconhecimento pela sociedade, por meio de determinação de um comportamento desejado da organização e dos objetivos que devem ser atingidos. E, considerando o pilar cultural-cognitivo, através da análise de experiências de sucesso de uso de TIC em instituições públicas e estímulo do governo para que as organizações implementem práticas semelhantes para obtenção de resultados satisfatórios com o uso de TIC.

Pressões coercitivas tendem a ser originadas de organizações dominantes no ambiente organizacional, principalmente com relação aos recursos, aos órgãos reguladores ou às matrizes empresariais, através da dominação (TEO et al., 2003; PFEFFER, SALANCIK, 1978). Teo et al. (2003) identificam na dependência da organização por clientes um tipo de pressão coercitiva ou quando a organização depende de um fornecedor que exige o uso de determinada tecnologia ou sistema a fim de aumentar seu benefício. Porém, uma das formas mais claras de pressão coercitiva é com relação às matrizes em que as filiais tendem a utilizar as mesmas normas e estruturas estipuladas pelas empresas

Proposição 1: As organizações públicas dependentes de recursos são coagidas a implementar práticas de governança eletrônica por organizações dominantes do seu 
campo organizacional, por pressões coercitivas.

Proposição 1a: A detenção de recursos por organizações dominantes impactam em pressões coercitivas para a implementação de práticas de governança eletrônica por organizações públicas dependentes, inseridas no ambiente organizacional.

As pressões normativas tendem a surgir quando aumenta a utilização de uma tecnologia por outras organizações que acabam sancionando essa tecnologia no ambiente organizacional (TEO et al., 2003). A influência na adoção de uma tecnologia aumenta com o compartilhamento de normas que se tornam consensuais de maneira mais fácil em um contexto de instituições similares. Assim como sugerem Pereira, Macadar e Becker (2012), com relação à adoção de um e-Serviço público, propõe-se que a implementação de práticas de governança eletrônica tende a ser influenciada pelo conhecimento e pela disseminação dos benefícios e custos dessa governança por outras organizações. Ainda, determinadas instituições podem acabar influenciando o comportamento organizacional das demais através do estabelecimento de normas (TEO et al., 2003). Nesse sentido, uma prática implementada por instituições públicas sancionados pelos governos tornase um padrão a ser adotado para aquisição de legitimidade pelas organizações (PEREIRA; MACADAR; BECKER, 2012). A partir dessas considerações, propõe-se o seguinte:

Proposição 2: As organizações públicas que necessitam aceitação no seu campo organizacional tendem a implementar práticas de governança eletrônica, por pressões normativas.

Proposição 2a: A existência de um comportamento desejado pelo ambiente organizacional reflete em pressões normativas de implementação de práticas de governança eletrônica por organizações públicas.

As pressões miméticas são normalmente impulsionadas pela análise dos resultados de uma prática que, quando positiva, gera uma influência de adoção dela pelas demais organizações por necessidade de reconhecimento e forças competitivas (PEREIRA; MACADAR; BECKER, 2012; TEO et al., 2003). Assim, a existência de modelos bem-sucedidos no ambiente organizacional acaba por gerar uma tendência em organizações concorrentes de copiarem o modelo adotado pelas demais. Segundo Rodriguez et al. (2007), o contrário pode ocorrer 
quando uma inovação é implantada por uma organização reconhecida e atinge com sucessos os seus objetivos, tornando-se, nesse caso, um modelo a ser seguido pelas demais instituições. Com isso, é proposto que:

Proposição 3: As organizações públicas que necessitam legitimidade tendem a utilizar modelos bem-sucedidos na implementação de práticas de governança, por pressões miméticas.
Proposição 3a: A existência de modelos bem-sucedidos de práticas de governança eletrônica no ambiente organizacional impacta em pressões miméticas de implementação dessas práticas por organizações públicas.

A Figura 1 apresenta o modelo conceitual construído neste estudo e resume as proposições apresentadas.

Figura 1 - Modelo conceitual

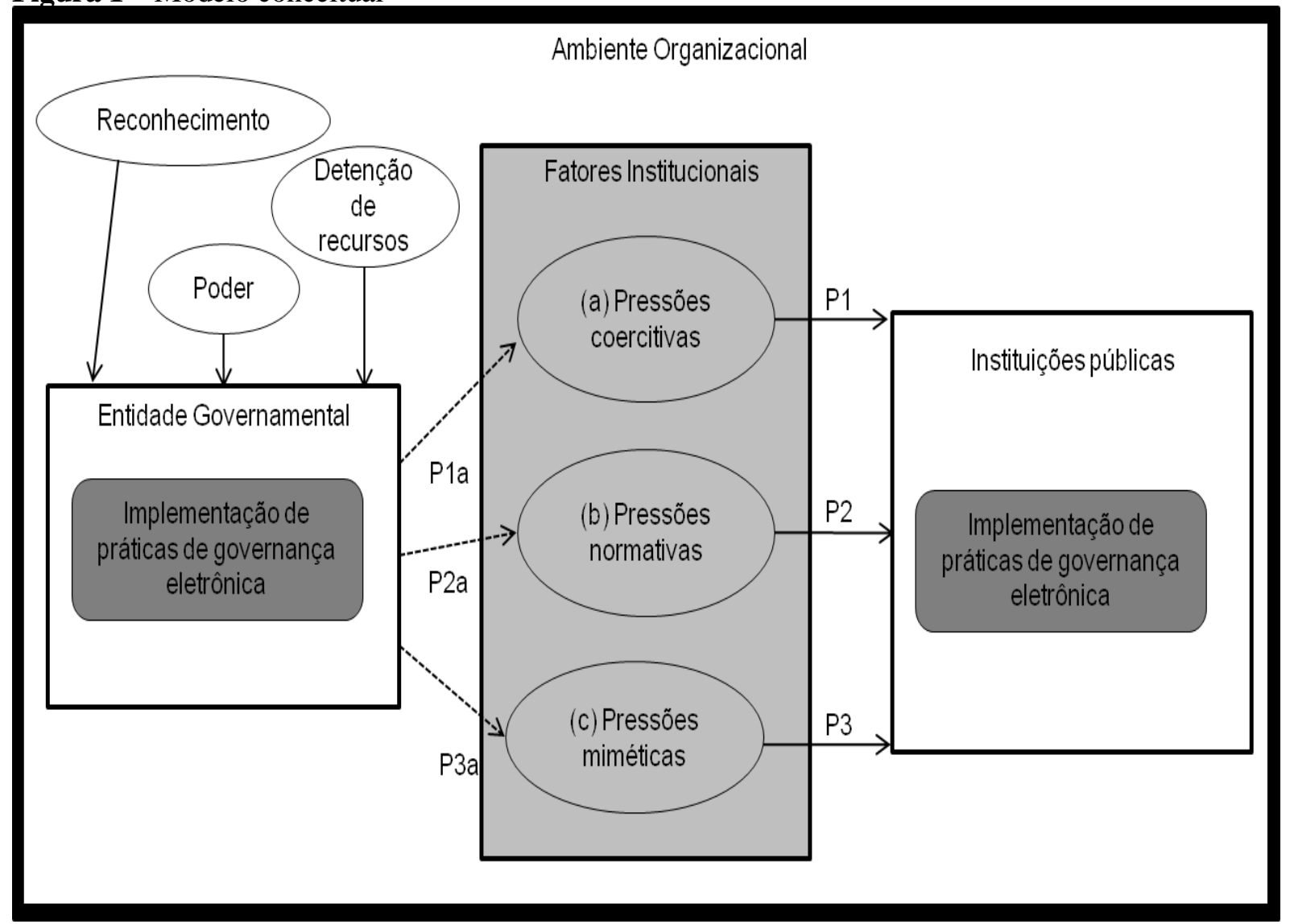

Fonte: os autores 
A dimensão dos fatores institucionais é o ponto central do modelo, em que são demonstradas a influência de pressões coercitivas, normativas e miméticas do contexto organizacional na implementação de práticas institucionalizadas de governança eletrônica. Buscou-se com essa categoria de análise identificar a necessidade de adaptação das organizações, para atender necessidades do governo na implementação dessas práticas e o impacto das forças institucionais para obtenção de legitimidade através de práticas bemsucedidas de governança eletrônica. Assim, consideraram-se aspectos abordados na fundamentação teórica sobre a teoria institucional como a tendência a homogeneidade das organizações em um campo organizacional, para obtenção de reconhecimento e a legitimidade perante as demais organizações através de pressões isomórficas para adoção de padrões de comportamento institucionalizados.

King et al. (1994) argumentam que os fatores institucionais são componentes essenciais para compreender a adoção de TIC que transpõem fronteiras organizacionais. Por esse motivo, optou-se pela análise dos fatores institucionais definidos por Scott (2008) e DiMaggio e
Powell (1983), que influenciam o ambiente organizacional através de pressões isomórficas coercitivas, normativas e miméticas.

\section{PROCEDIMENTOS METODOLÓGICOS}

Considerando que a questão de investigação é "como os fatores institucionais influenciam as organizações para a implementação de práticas de governança eletrônica?", optou-se por uma pesquisa de natureza qualitativa, tendo em vista a necessidade de compreender profundamente o contexto institucional. Quanto aos objetivos, a pesquisa tem caráter exploratório, uma vez que se busca uma melhor compreensão do fenômeno estudado por meio de modelo teórico previamente estabelecido.

Assim, foi realizado um estudo de caso, que, segundo Godoy (2006, p. 124), contém a descrição do fenômeno estudado e “[...] busca encontrar padrões nos dados e desenvolver categorias conceituais que permitam ilustrar, confirmar ou opor-se a suposições teóricas”. A seleção do caso seguiu o conceito definido por Flick (2004) da seleção gradual de um caso particularmente típico. Optou-se pela análise de um caso único de forma consistente, antes de empreender uma análise comparativa de casos, conforme adverte Flick (2004). 
Os critérios adotados para a seleção do caso foram os seguintes: (1) organização pública em âmbito nacional, a fim de identificar influências oriundas de organizações de todo o país, além de influências internacionais; (2) organização da área de Educação, vinculada ao Ministério da Educação (MEC), por se tratar de uma área estabelecida com práticas de governo eletrônico; (3) organização com pelo menos um e-Serviço público implantado. Com base nesses critérios, foi selecionada a Capes, uma vez que se trata de uma instituição pública vinculada ao MEC e com práticas de governo eletrônico estabelecidas e reconhecidas em âmbito nacional e internacional, como o Portal de Periódicos da Capes. O Portal de Periódicos da Capes foi um dos premiados no $15^{\mathrm{o}}$ Concurso Inovação na Gestão Pública Federal promovido pela Escola Nacional de Administração Pública (Enap) (PORTAL DE PERIÓDICOS CAPES, 2011).

A coleta de dados da presente pesquisa ocorreu através de entrevistas individuais, entrevista em grupo, além da profunda revisão da literatura e da análise documental. As entrevistas ocorreram de maneira semiestruturada, com base em um roteiro de entrevista previamente estabelecido pelas pesquisadoras. Os documentos analisados são de informações oriundas do site da Capes, da Portaria $n^{\circ}$
2.424 de 2002 do MEC, que versa sobre o regimento interno da Capes, e da dissertação de Almeida (2006), que também estudou o Portal.

Foram contatados representantes da organização estudada, tendo sido realizada entrevista com o ex-presidente da Capes, que em 2000 participou ativamente da criação do Portal, com a Coordenação Geral do Portal de Periódicos (CGPP) detentora dessa função atualmente e quando o portal foi concebido, com a Coordenação Geral de Informática (CGIN) da Capes, que participou da atualização do portal em 2009, com um analista de tecnologia envolvido diretamente com a TIC do Portal e com uma representante regional do Portal, que também acompanhou a criação do mesmo em 2000. Além de representantes da Capes, foram entrevistados bibliotecários de Instituições de Ensino Superior (IES) usuárias do Portal desde a sua implementação, em 2000. Foi realizada uma entrevista em grupo com três bibliotecários de uma IES privada, uma entrevista individual com outra bibliotecária da mesma instituição e uma entrevista individual com a bibliotecária responsável pelo Portal de Periódicos da Capes em uma IES pública. Assim, foram 10 entrevistados que, durante o processo de análise dos dados, foram identificados por números para garantir o 
sigilo e a confidencialidade dos depoimentos de cada participante.

As entrevistas individuais ocorreram em sua maioria de maneira presencial, exceto com os representantes da Diretoria de Gestão (DGES) da Capes, que aconteceu por telefone por motivos de agenda, com duração aproximada de 40 minutos. A coleta de dados com a Coordenadora Geral do Portal foi realizada através de um questionário adaptado do roteiro de entrevista (a entrevistada alegou não ter disponibilidade para realização da entrevista presencial/via telefone). Para complementar o questionário, utilizou-se a análise documental. Os bibliotecários que participaram da entrevista em grupo fazem parte da equipe desde um período anterior à implantação do Portal de Periódicos da Capes na instituição. Tal entrevista foi realizada de forma presencial e teve duração de uma hora. $\mathrm{O}$ período de execução das entrevistas foi de setembro de 2011 a novembro de 2011. A análise documental ocorreu ao longo do ano de 2011.

Optou-se pelo método de análise de conteúdo para a realização da análise dos dados coletados. A organização da análise de dados desta pesquisa ocorreu em fases, conforme propõe Bardin (1977): a préanálise, a exploração do material, e o tratamento dos resultados e interpretação. A dimensão definida no modelo conceitual como "Fatores Institucionais" foi definida na análise dos dados como uma categoria de análise composta por três subcategorias, a saber: a) Pressões coercitivas; b)

\section{Pressões normativas; c) Pressões} miméticas.

Antes de proceder à análise e discussão dos dados, foi realizado um breve relato do e-Serviço "Portal de Periódicos da Capes" iniciado em 2000.

\subsection{O Portal de Periódicos da Capes}

O Portal de Periódicos da Capes é um serviço prestado pela Capes à sociedade desde novembro de 2000, consistindo em uma biblioteca virtual que disponibiliza conteúdos da produção científica mundial às instituições de ensino e pesquisa no Brasil (PORTAL DE PERIÓDICOS DA CAPES, 2011).

Segundo o Portal de Periódicos da Capes (2011), o Portal foi criado tendo em vista o déficit de acesso das bibliotecas brasileiras à informação científica internacional, com o objetivo de reduzir os desnivelamentos regionais no acesso à informação no Brasil. "Ele é considerado um modelo de consórcio de bibliotecas único no mundo, pois é inteiramente financiado pelo governo brasileiro", sendo a iniciativa do gênero com a maior capilaridade no planeta, cobrindo todo o território nacional (PORTAL DE PERIÓDICOS DA CAPES, 2011). 
O Portal de Periódicos tem como missão "promover o fortalecimento dos programas de pós-graduação no Brasil por meio da democratização do acesso online à informação científica internacional de alto nível” (PORTAL DE PERIÓDICOS DA

CAPES, 2011). De acordo com Almeida (2006), o e-Serviço se consolidou como uma ferramenta de acesso à informação científica importante, acarretando em aceitação do modelo e tornando-se uma boa prática na pesquisa pelas IES.

A história do Portal de Periódicos da Capes

[...] remonta ao ano de 1990 quando, com o objetivo de fortalecer a pósgraduação no Brasil, o Ministério da Educação criou o programa para bibliotecas de Instituições de Ensino Superior. Foi a partir dessa iniciativa que, cinco anos mais tarde, foi criado Programa de Apoio à Aquisição de Periódicos (PAAP). O Programa está na origem ao atual serviço de periódicos eletrônicos oferecido à comunidade acadêmica brasileira pela Capes (PORTAL DE PERIÓDICOS DA CAPES, 2011).

A criação do Portal ocorreu no ano de 2000, ao mesmo tempo em que as bibliotecas virtuais começaram a ser criadas e as editoras iniciavam o processo de digitalização dos seus acervos. Com o Portal, a Capes passou a centralizar e otimizar a aquisição desse tipo de conteúdo, através da negociação direta com editores internacionais (PORTAL DE PERIÓDICOS DA CAPES, 2011).
Em 2001, o Portal de Periódicos ganhou uma regulamentação específica, tendo como finalidade facilitar e promover o acesso à informação científica e tecnológica nacional e internacional. Segundo o Portal de Periódicos da Capes (2011), até esse ano, os recursos financeiros da Capes eram repassados diretamente às IES para a manutenção de coleções impressas, e, a partir de 2002, esses recursos foram centralizados pela Capes, que começou a investir nos periódicos eletrônicos e na ampliação e atualização do conteúdo do Portal.

Segundo o Portal de Periódicos da Capes (2011), nos dez anos de existência do Portal, o seu acervo cresceu, a quantidade de instituições participantes também evoluiu, e o Portal consolidou-se como uma das maiores bibliotecas virtuais do mundo, disponibilizando conteúdos fundamentais à pesquisa brasileira. Como vantagens do Portal, tem-se: facilidade de acesso à informação científica; acesso a conhecimento atualizado; democratização do acesso à informação; inserção internacional do conhecimento científico.

\section{APRESENTAÇÃO E DISCUSSÃO DOS RESULTADOS}

Com base no modelo conceitual proposto na pesquisa, foi construído o 
Quadro 1 com as categorias e subcategorias de análise empregadas na coleta de dados. Para cada categoria proposta na pesquisa são apresentadas as evidências empíricas coletadas tanto nas entrevistas como na análise de documentos.

Após o quadro, é apresentada a discussão dos dados e os resultados da pesquisa.

Quadro 1 - Evidências empíricas da categoria "Fatores institucionais"

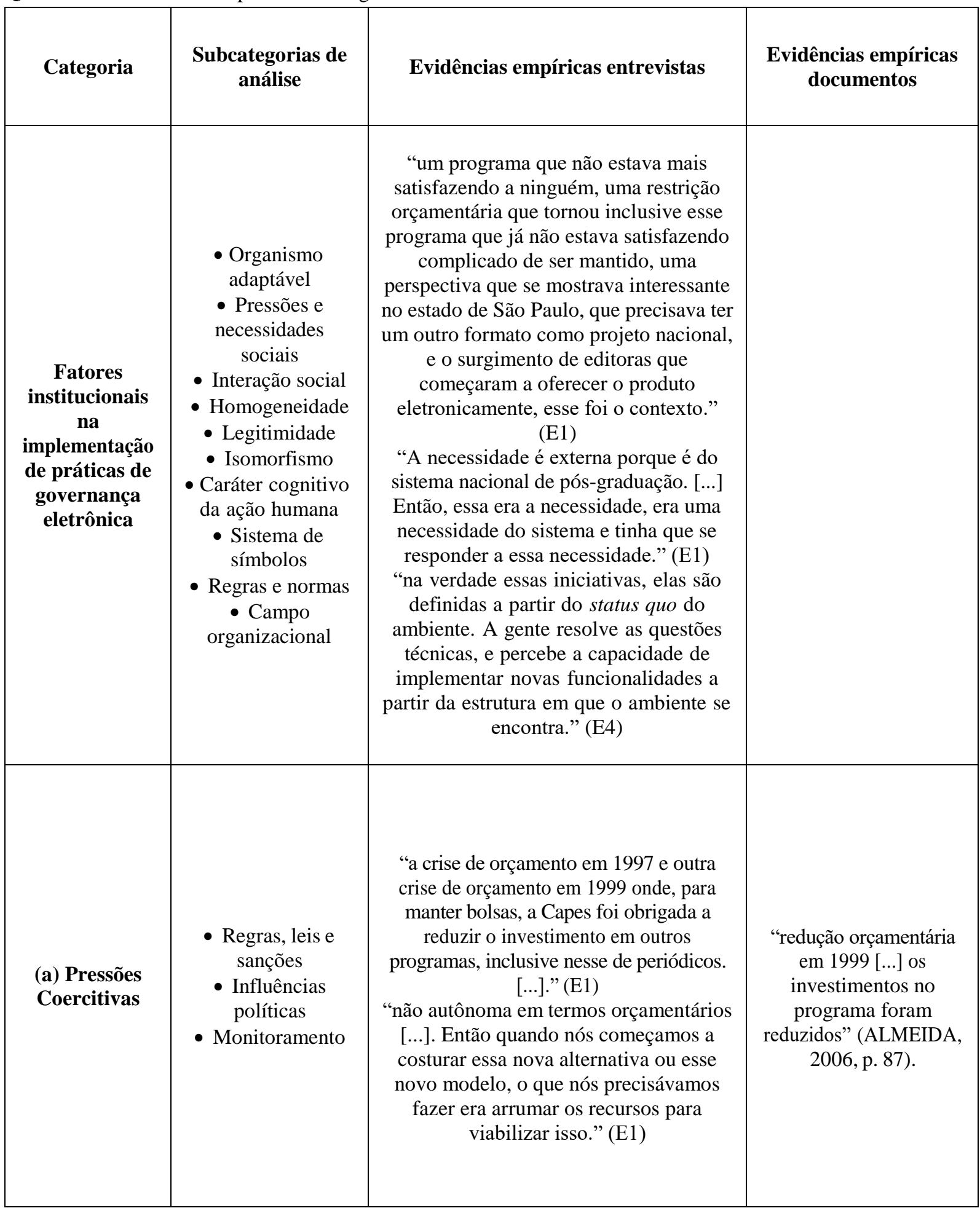




\begin{tabular}{|c|c|c|c|}
\hline $\begin{array}{l}\text { (b) Pressões } \\
\text { normativas }\end{array}$ & $\begin{array}{c}\text { • Certificação } \\
\text { • Aceitação } \\
\text { - Valores e Normas }\end{array}$ & $\begin{array}{l}\text { "a Capes pensava em fazer o seu papel, o } \\
\text { papel da Capes é fazer isso, ou seja, } \\
\text { tentar detectar quais são as demandas e } \\
\text { as necessidades do sistema de pós- } \\
\text { graduação e de pesquisa e responder." } \\
\text { (E3) } \\
\text { "a criação da RNP em } 1990 \text { e a } \\
\text { constituição de um Comitê Gestor da } \\
\text { Internet no Brasil representam o } \\
\text { direcionamento para a implementação de } \\
\text { práticas de governo eletrônico." (E2) } \\
\text { "houve uma enorme sintonia entre a } \\
\text { capacidade de demonstração da Capes da } \\
\text { importância do programa e a } \\
\text { receptividade do ministério e do governo } \\
\text { de um modo geral e os recursos foram } \\
\text { assegurados, então foram assegurados } \\
\text { inclusive com uma perspectiva de } \\
\text { aumento." (E1) }\end{array}$ & \\
\hline $\begin{array}{l}\text { (c) Pressões } \\
\text { miméticas }\end{array}$ & $\begin{array}{l}\text { - Crenças comuns } \\
\text { - Isomorfismo } \\
\text { - Modelos bem- } \\
\text { sucedidos }\end{array}$ & $\begin{array}{l}\text { "Teve como fonte inspiradora a experiência } \\
\text { da Fapesp, que tinha implantado o ProBe, } \\
\text { reunindo, em consórcio, instituições de } \\
\text { Ensino e Pesquisa situadas no estado de São } \\
\text { Paulo e três Fundações. O êxito dessa } \\
\text { experiência contribuiu para o planejamento } \\
\text { do Portal de Periódicos, com dimensão mais } \\
\text { ampla para atender instituições de Ensino e } \\
\text { Pesquisa de todo o país." (E2) } \\
\text { "Tinha uma experiência que mostrava } \\
\text { que essa história do acesso eletrônico de } \\
\text { um ou de outro jeito não era inviável." } \\
\text { (E1) } \\
\text { “em São Paulo surgiu o programa } \\
\text { ProBE, Programa Biblioteca Eletrônica, } \\
\text { que teve a configuração que o portal veio } \\
\text { a ter posteriormente. Então, eu te diria } \\
\text { que o grande modelo, vamos dizer assim, } \\
\text { que teve uma influência bastante grande } \\
\text { no portal foi o ProBE, em São Paulo. [...] } \\
\text { O ProBe em termos de biblioteca } \\
\text { eletrônica tipo o portal foi um modelo } \\
\text { que pode ser seguido.” (E3) } \\
\text { "a história do portal iniciou com uma } \\
\text { iniciativa de São Paulo, da biblioteca } \\
\text { digital, na Fapesp.” (E8) } \\
\text { "Então, eles olharam outras iniciativas } \\
\text { antes até começarem realmente as } \\
\text { negociações do portal.” (E8) } \\
\text { "havia experiências sim muito } \\
\text { interessantes. (...) Então, havia coisas } \\
\text { andando no cenário internacional, não } \\
\text { como o Brasil concebeu, não como uma } \\
\text { rede aberta para instituições } \\
\text { universitárias, as coisas eram mais } \\
\text { focadas ou eram de instituições ou eram } \\
\text { de redes de pesquisa. [...] Então, há um } \\
\text { aspecto de coisa única, mas havia } \\
\text { experiências sobre as quais a gente pode } \\
\text { construir um projeto." (E1) }\end{array}$ & $\begin{array}{l}\text { “A Fapesp já tinha } \\
\text { implementado o ProBE, } \\
\text { que foi lançado em maio } \\
\text { de } 1999 \text { [...].” } \\
\text { (ALMEIDA, 2006, p. } \\
\text { 89). } \\
\text { “O ProBE consolidou-se } \\
\text { assim como mais uma } \\
\text { iniciativa da Fapesp no } \\
\text { sentido de expandir e } \\
\text { enriquecer os serviços e } \\
\text { recursos de informação } \\
\text { especializada } \\
\text { indispensáveis às } \\
\text { atividades da } \\
\text { comunidade científica do } \\
\text { estado de São Paulo. [...] } \\
\text { Essa iniciativa } \\
\text { apresentava-se como } \\
\text { exitosa e eficiente } \\
\text { naquele estado". } \\
\text { (ALMEIDA, 2006, p. } \\
\text { 90). } \\
\text { “O OhioLINK [...] (a) } \\
\text { caracterizar-se como } \\
\text { instituição pioneira na } \\
\text { atividade de acesso } \\
\text { eletrônico a informação } \\
\text { científica; (b) por abrigar } \\
\text { localmente os conteúdos } \\
\text { a serem disponibilizados; } \\
\text { (c) representar um } \\
\text { empreendimento } \\
\text { mundialmente } \\
\text { reconhecido e de alta } \\
\text { performance técnica e } \\
\text { operacional.”" } \\
\text { (ALMEIDA, 2006, p. } \\
\text { 67). }\end{array}$ \\
\hline
\end{tabular}

Fonte: os autores. 
Conforme sugerido por Scott (2008) foi identificada a influência de fatores regulatórios, normativos e culturalcognitivos na adoção de TIC pela organização inserida no contexto da administração pública. A organização é influenciada fortemente pelo status quo do ambiente, no sentido de ser dependente de tecnologias e serviços conforme estes vão sendo disponibilizados. Os fatores institucionais identificados como influenciadores do processo de tomada de decisão para criação do e-Serviço foram a dependência pela organização de recursos do MEC, o incentivo do governo federal como forma de sanção, o papel da organização e o consequente comportamento desejado no ambiente organizacional, a aceitação do serviço por instituições maiores como o MEC e o governo federal e a existência de modelos a ser seguidos como os consórcios internacionais e o Programa do Estado de São Paulo através da crença comum socialmente construída.

Assim, ao recorrer ao pilar regulatório da teoria institucional, foi identificada a existência de uma dependência da organização por instituições maiores, tanto em termos orçamentários como através de influência política, conforme sugerem King et al. (1994) e Rodriguez et al. (2007) que consideram as autoridades governamentais uma força institucional impactante no comportamento das demais organizações. Ou seja, a detenção de recursos por organizações dominantes, sendo elas o MEC e o governo federal, e a redução do orçamento da organização analisada influenciaram coercivamente na implementação do e-Serviço, pois seria inviável dar continuidade ao serviço da forma como era feito anteriormente, sem o uso de TIC.

Posteriormente, também se percebeu um incentivo federal para continuidade do e-Serviço na forma de recursos, demonstrando a manipulação de sanções, conforme prevê Scott (2008), a fim de influenciar o comportamento da organização. Assim, as proposições 1 e 1a do modelo conceitual são corroboradas, no sentido de que as organizações públicas dependentes de recursos e de influências políticas sofrem pressões coercitivas de implementação de práticas de governança eletrônica por organizações dominantes e detentoras de recursos.

Ainda no pilar regulatório, foi possível identificar uma dependência da organização com relação ao avanço tecnológico de empresas provedoras de serviços para modernização do e-Serviço público prestado, conforme propuseram Teo et al. (2003). A principal dependência se dá pelas editoras, que necessariamente devem ofertar as coleções em meio 
eletrônico para aquisição pela organização e disponibilização no Portal de Periódicos. Outra dependência existente é com relação à empresa provedora do serviço de busca e pela RNP que viabiliza a funcionalidade de acesso remoto ao portal.

O pilar normativo também foi recorrente ao analisar a organização, pois foi identificado um comportamento desejado de atuação da organização devido o seu papel na comunidade acadêmica, no acesso e divulgação da produção científica. Ou seja, há uma necessidade de aceitação e reconhecimento da organização no contexto em que está inserida, nesse caso por IES, institutos de pesquisa e pelo MEC e governo federal, no sentido de cumprir o seu papel na sociedade. Na mesma linha, conforme instituições relevantes sancionam uma prática que se torna consensual, aumentam as pressões normativas sobre essa prática, potencializando a sua influência no comportamento organizacional, conforme Teo et al. (2003). Nesse sentido, a sanção do MEC potencializou a influência para implementação do e-Serviço público pela organização. Assim, as proposições 2 e 2 a do modelo conceitual são corroboradas, no sentido de que as organizações públicas que necessitam aceitação no seu campo organizacional sofrem pressões normativas de implementação de práticas de governança eletrônica devido à existência de um comportamento desejado pelo ambiente organizacional.

O pilar cultural-cognitivo pode ser analisado na existência de uma crença comum sobre os benefícios da prestação eletrônica de serviços pela organização, tendo em vista a existência de experiências legítimas na disponibilização da informação eletrônica em mídia eletrônica, pois geraram bons resultados. Apesar de não existir um portal provido pelo governo em outros países, havia consórcios internacionais de centralização de conteúdo eletrônico entre universidades e institutos de pesquisa, com recursos providos por essas instituições, sendo experiências bem-sucedidas que serviram como base para criação do portal no país. Além disso, foi identificada uma influência considerável do Programa Biblioteca Eletrônica (ProBE)( Programa financiado pela FAPESP que tem como objetivo o apoio ao desenvolvimento da pesquisa científica no Estado de São Paulo (PROBE, 2011)), como um modelo bemsucedido a ser seguido, porém devendo ser ampliado para atender todo o sistema nacional e não um estado específico. Assim, as proposições 3 e 3 a do modelo conceitual são corroboradas, no sentido de que as organizações públicas que necessitam legitimidade no seu campo organizacional sofrem pressões miméticas de implementação de práticas de 
governança eletrônica devido à existência de modelos bem-sucedidos no ambiente organizacional.

Ainda no pilar cultural-cognitivo, foi identificado o mimetismo na adoção do software que provê suporte a algumas funcionalidades do portal, sendo a prática de adoção desse software reconhecida mundialmente, promovendo credibilidade ao serviço prestado pela organização. $\mathrm{Ou}$ seja, a utilização do software por instituições no mundo inteiro impactou em pressões miméticas de adoção do mesmo software pela organização para maior legitimidade do serviço prestado, através de uma prática reconhecida no ambiente organizacional.

Com base nesta discussão emergem os resultados da pesquisa, conforme ilustra a Figura 2. Nela são representados os principais fatores institucionais identificados nesta pesquisa, que se tornam mecanismos coercitivos, normativos e miméticos no condicionamento do comportamento organizacional, corroborando com as proposições do modelo conceitual.

Figura 2 - Modelo de resultados

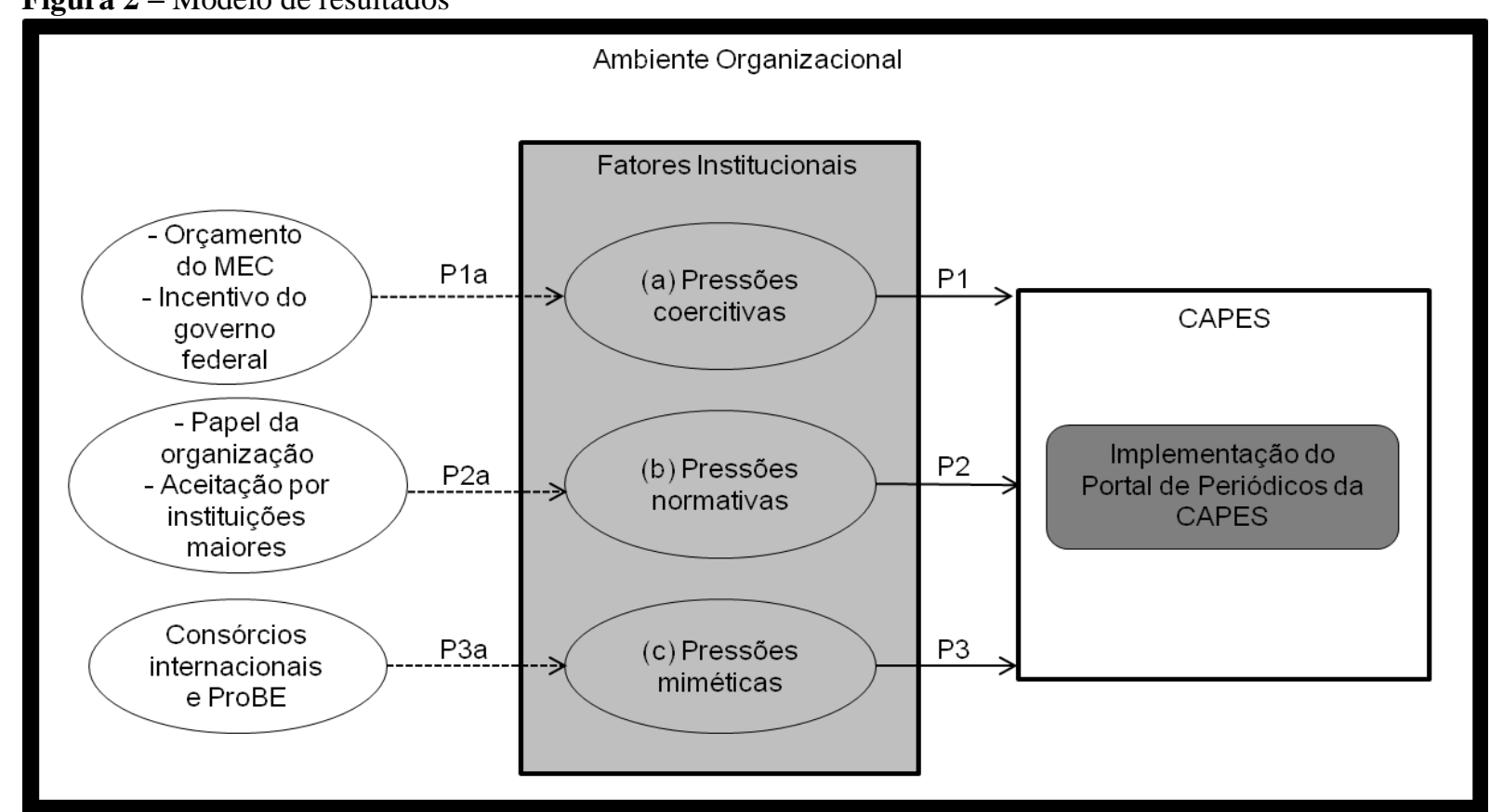

Fonte: os autores.

A tomada de decisão para a adoção de TIC na prestação do serviço público analisado ocorreu pelos altos gestores da organização optaram pela implementação do e-Serviço, e foi influenciada por fatores externos à organização.
Os altos gestores ao optarem pela implementação do portal, consideraram o ambiente organizacional em que estavam inseridos e as pressões oriundas desse ambiente. Tratava-se de um contexto de dependência de recursos de 
instituições maiores, necessidade de atendimento de uma demanda da comunidade científica, um incentivo do governo federal para dar continuidade ao serviço anteriormente prestado sem o uso de TIC, a necessidade de ampliação do alcance do serviço, além da redução de custos. Ou seja, havia diversos fatores institucionais à época que influenciaram a organização pela busca de uma alternativa para a melhoria na prestação do serviço, sendo o uso de TIC a opção mais favorável para geração de valor à sociedade através da prestação de um e-Serviço público.

Além disso, outro fator que motivou a implementação do e-Serviço foi a existência de modelos de referência e experiências (inclusive internacionais) de sucesso no uso de TIC para prover o acesso à informação. Tendo como base outros modelos, foi possível perceber que a ação era viável e trazia a melhoria necessária na prestação de serviços públicos pela organização.

Assim, como resultados da pesquisa tem-se que a instituição pública sofreu influência de fatores externos para implementação do e-Serviço analisado, ou seja, na implantação de uma prática de governança eletrônica. A análise do ambiente governamental mostrou que a organização pública é dependente de diversos fatores do campo em que está inserida, sofrendo pressões isomórficas de organizações influentes e do próprio ambiente. Essa afirmação confirma o que propuseram Pfeffer e Salancik (1978), de que as organizações dependem de legitimidade social e de instituições influentes, necessitando de apoio do ambiente organizacional e estando sujeitas a pressões externas e controle do seu comportamento organizacional. Adicionalmente, por se tratar de uma organização com um papel bem definido no ambiente organizacional, necessita legitimidade e reconhecimento social e econômico, e conforme propôs Teo et al. (2003), o faz mediante a adoção de tecnologia para modernização dos serviços prestados.

\section{CONSIDERAÇÕES FINAIS}

O ponto principal deste artigo foi verificar como os diferentes fatores institucionais influenciam na implementação de práticas de governança eletrônica por organizações públicas. Identificou-se que a instituição pública sofreu influência de fatores externos - na forma de pressões coercitivas, normativas e miméticas para implementação do e-Serviço analisado, ou seja, na implantação de uma prática de governança eletrônica.

Esta pesquisa permitiu a identificação de fatores regulatórios, normativos e cultural-cognitivos através 
de mecanismos coercitivos, normativos e miméticos existentes no contexto governamental que condicionam o comportamento de instituições na adoção de TIC para prestação de serviços. Foi possível perceber o impacto do contexto organizacional na adoção de TIC por instituições públicas para implementação de serviços, conforme sugerido por Diniz et al. (2009) ao afirmarem que as organizações sofrem influência de fenômenos sociais, políticos, econômicos e tecnológicos no desenvolvimento de práticas de gestão pública.

Entre os principais achados do estudo pode-se destacar o fato que a implementação do Portal, objetivando apoiar os programas de pós-graduação brasileiros, pode ser atribuída pela dependência da CAPES por instituições maiores em termos financeiros e também por influência política oriundas do Ministério da Educação e do Governo Federal. Tais fatores geram pressões coercitivas como a redução do recurso orçamentário da instituição, que teve necessidade de utilizar a TIC para disponibilizar periódicos às universidades.

Outro fator que influenciou na implementação do portal, e se caracteriza como pressão normativa, é a identificação de um comportamento desejado de atuação da CAPES devido a sua posição no âmbito acadêmico no que se refere ao acesso e à divulgação da produção científica. Além disso, quando instituições importantes ratificam uma prática, ela se torna consenso nesse ambiente.

Sobre o pilar cultural-cognitivo, ou mais conhecido como pressões miméticas, estas foram oriundas de modelos bem sucedidos de iniciativas existentes no cenário educacional, podendo citar casos como o ProBE e consórcios internacionais de centralização de conteúdo entre universidades.

Assim, pode-se afirmar que as proposições concebidas neste estudo foram confirmadas. É possível perceber a importância do ambiente, através de fatores institucionais, no condicionamento organizacional e a influência que exerce na tomada de decisão para implementação de práticas de governança eletrônica nas organizações. Identificou-se que as organizações necessitam de aprovação social, e sanção de instituições maiores, inclusive por dependerem de recursos dessas organizações.

Este artigo, apesar de promover uma consistente reflexão sobre a governança eletrônica em instituições públicas a partir de uma perspectiva institucional, não possui proposições exaustivas, sendo sugeridos, a partir desta 
pesquisa, estudos futuros. A replicação do modelo conceitual proposto na pesquisa em outras dimensões da governança eletrônica como a e-Democracia e a eAdministração pública pode trazer fatores institucionais complementares que condicionam o comportamento das instituições públicas na implementação de práticas de governança eletrônica. Além disso, sugere-se também a aplicação do modelo conceitual em casos internacionais devido às evidências de que o e-Serviço prestado pela organização estudada serviu como modelo para entidades governamentais em outros países, influenciando mimeticamente o ambiente organizacional.

\section{REFERÊNCIAS}

ALMEIDA, E. C. E. de. O portal de periódicos da CAPES: estudo sobre a sua evolução e utilização. 2006. 175 f., il. Dissertação (Mestrado em Desenvolvimento Sustentável) Universidade de Brasília, Brasília, 2006.

AVGEROU, C. The significance of context in information systems and organizational change. Information Systems Journal, n.11, p.43-63, 2001.

BARBOSA, A. F.; FARIA, F. I.; PINTO, S. L. Governança eletrônica no setor público. In: KNIGHT, P. T.; FERNANDES, C. C. C.; CUNHA, M. A. (Orgs). e-Desenvolvimento no Brasil e no mundo: subsídios e Programa e-Brasil. São Caetano do Sul: Yendis Editora, 2007.

\section{BARDIN, L. Análise de Conteúdo.} Lisboa: Edições 70, 1977.

\section{CASTELlS, M. A Sociedade em Rede.} São Paulo: Paz e Terra, 1999.

CUNHA, M. A.; ANNENBERG, D.; AGUNE, R. M. Prestação de serviços públicos eletrônicos ao cidadão. In: KNIGHT, P. T.; FERNANDES, C. C. C.; CUNHA, M. A. (Orgs). e-

Desenvolvimento no Brasil e no mundo: subsídios e Programa e-Brasil. São Caetano do Sul: Yendis Editora, 2007.

DIMAGGIO, P. J.; POWELL, W. W. The iron cage revisited: Institutional isomorphism and collective rationality in organizational fields. American

Sociological Review, v.48, n.2, p.147-160, 1983.

DINIZ, E. H.; BARBOSA, A. F.; JUNQUEIRA, A. R. B.; PRADO, O. O governo eletrônico no Brasil: perspectiva histórica a partir de um modelo estruturado de análise. RAP, Rio de Janeiro, v.43, n.1, p.23-48, 2009.

\section{FLICK, U. Uma introdução à Pesquisa}

Qualitativa. 2.ed. Porto Alegre: Bookman, 2004.

GIL-GARCIA, J.R.; LUNA-REYES, L.F. Integrating Conceptual Approaches to EGovernment. In: KHOSROW-POUR, M. (ed.). Encyclopedia of e-commerce, egovernment, and mobile commerce. Idea Group Inc. pp. 636-643, 2006, GODOY, C. Pesquisa qualitativa em estudos organizacionais: paradigmas estratégias e métodos. São Paulo: Saraiva, 2006.

KING, J. L.; GURBAXANI, V.; KRAEMER, K. L.; McFARLAN, F. W., RAMAN, K. S.; YAP, C. S. Institutional Factors in Information Technology Innovation. Information Systems Research, v.5, n.2, p.139-169, 1994. 
MACHADO-DA-SILVA, C. L., FONSECA, V. S.; CRUBELLATE, J. M. Estrutura, Agência e Interpretação: elementos para uma abordagem recursiva do processo de institucionalização. RAC, Edição Especial 2010, art.4, p.77-107, 2010.

MEC. Portaria $\mathbf{n}^{\mathbf{0}} \mathbf{2 . 4 2 4}$ de 28 ago. 2002. Disponível em: <http://www.capes.gov.br/images/stories/ download/legislacao/Portaria_MEC_242 4_2002.pdf>. Acesso em: 31 jan. 2012.

PFEFFER, J.; SALANCIK, G. External Control of Organizations: A Resource Dependence Perspective. Harper and Row, New York, 1978.

Portal de Periódicos da CAPES.

Institucional. [2011]. Disponível em: $<$ http://www.periodicos.capes.gov.br.ez94. periodicos.capes.gov.br/>. Acesso em: 20 de jan. 2012.

ProBE. [2011]. Disponível em:< http://probe.bvs.br/index1.php?home=true >. Acesso em: 15 de dez. 2011.

RODRIGUEZ, C. L.; DINIZ, E. H.; FERRER, F. Influência governamental e estratégias institucionais na difusão de inovações em economias emergentes.

RAE, v.47, n.1, 2007.

SCOTT, W. R. Institutional theory P40814 in Encyclopedia of Social Theory, George Ritzer, ed. Thousand Oaks, CA: Sage, 2004.

Institutions and organizations: ideas and interests. 3. ed. Thousand Oaks: Sage, 2008.

TEO, H. H.; WEI, K. K.; BENBASAT, I. Predicting intention to adopt interorganizational linkages: An institutional perspective. MIS Quarterly, v.27, n.1, Mar, p.19-49, 2003. 